\section{TATRA \\ MOUNTaiNS \\ Mathematical Publications}

DOI: $10.2478 /$ tmmp-2020-0003

Tatra Mt. Math. Publ. 75 (2020), 33-48

\title{
ESTIMATING THE DOMESTIC SHORT RATE IN A CONVERGENCE MODEL OF INTEREST RATES
}

\author{
Zuzana BučKová - Zuzana Girová - BeÁta Stehlíková \\ Faculty of Mathematics, Physics and Informatics, Comenius University, Bratislava, SLOVAKIA
}

\begin{abstract}
In this paper we study the convergence model of interest rates by Corzo and Schwartz. It models the situation when a country is going to enter a monetary union, for example the eurozone. We are interested in estimating the underlying short rate, which is a theoretical variable, not observed on the market. We use the procedure already employed for the Vasicek model to the eurozone data and for the case of a zero correlation we show that a similar procedure can be used also for the estimation of the domestic parameters and the short rate values. The assumption of the zero correlation allows us to simplify the optimization problem, but using simulations we show that our algorithm is robust to the specification of the correlation. It estimates the short rate with a high precision also in the original case of a nonzero correlation, as well as in the case of a dynamic correlation, when the correlation is modelled as a function of time. Finally, we use the algorithm to real market data and estimate the short rate before adoption of the euro currency in Slovakia, Estonia, Latvia and Lithuania.
\end{abstract}

\section{Introduction}

Modelling interest rates is an important task in financial mathematics. Through discounting they enter any financial valuation which considers cash flows at different times. There are also financial derivatives which have a payoff depending on interest rates (the so-called interest rate derivatives) and their valuation requires a meaningful model for the interest rates. Short rate models are based on a stochastic differential equation (or a system of such equations) governing the instantaneous interest rate, the so-called short rate. The other interest rates are then obtained from the bond prices. A discount zero coupon bond is a security which pays a unit amount of money at a specified time $T$,

(C) 2020 Mathematical Institute, Slovak Academy of Sciences.

2010 Mathematics Subject Classification: 91G30, 35K15, 62M20.

Keywords: interest rates, short rate, convergence model, calibration.

The work was supported by VEGA 01/0062/18 grant.

Licensed under the Creative Commons Attribution-NC-ND4.0 International Public License. 


\section{ZUZANA BUČKOVÁ-ZUZANA GIROVÁ-BEÁTA STEHLÍKOVÁ}

called maturity of a bond. If we denote the price of such a bond at time $t$ as $P(t, T)$, then it is linked with the corresponding interest rate $R(t, T)$ under continuous compounding by formula

$$
P(t, T)=e^{-R(t, T)(T-t)}, \quad \text { resp. } \quad R(t, T)=-\frac{\log P(t, T)}{T-t} .
$$

The bond prices are obtained from the solution to a parabolic partial differential equation which contains model parameters from the stochastic process describing the short rate and the so-called market price of risk. For a detailed treatment of pricing bonds using the partial differential equations approach we refer the reader to 9 .

There is a variety of approaches for the formulation of the stochastic process for the short rate. It can be given by a single stochastic differential equation; mean-reversion models include classical Vasicek [17] and Cox-Ingersoll-Ross [5] models, nonlinear drift was studied for example in [1, another approach is a cyclical model proposed in [10. An addition of another stochastic factor can be performed in different ways. One of them is making a certain parameter from a one-factor model stochastic; it leads for example to models with stochastic volatility, see [6] for a comprehensive review. Another possibility is adding a new stochastic quantity, which directly influences the short rate.

In this paper we consider a special group of models of this kind. We study short rate models, which are used to model a situation when a country is going to enter a monetary union or the domestic interest rate is strongly influenced by an interest rate in another country. As a typical example we can consider a situation in a country before entering the eurozone. A pioneering paper in this regard is [3] which uses a one-factor Vasicek model [17] to model the European short rate. The domestic short rate is modelled as being influenced by the European one. There are different possible modifications of this approach. For example, 18] considers a model with nonlinear volatilities, while [4] studies the model in a nonparametric setting. Paper [1] suggests using a multifactor model also for the European short rate, which leads to a three-factor model for the domestic rate.

Our aim is the estimation of the unobservable short rate. It is necessary when evaluating prices of any short rate derivatives obtained by solving a partial differential equation. Also, its behaviour provides interesting information about the economy. We consider the approach of [8] (for the Vasicek model) and [2] (for the short rate as a sum of two unobservable processes), which uses a least squares methodology applied to the data of interest rates with different maturities. Furthermore, since Vasicek model is a building block of the convergence model which we consider, the algorithm [8] will serve as a first step of our estimation procedure. This approach is similar to the estimation of [13] and [14], 
where such an objective function was used to estimate the parameters of the model, with short rate approximated by an interest rate with short maturity. We note that in these papers, even though only the parameters were estimated, the optimization problem was complicated and genetic algorithms were used to compute the optimal solution. Therefore, we take a different approach - we find a simple case of the model which allows us to simplify the optimization procedure, and then we study the robustness of the algorithm when applied to data generated by a more complicated model. Finally, we remark that using the least squares approach at different stages of estimation is a popular choice also in other approaches, for example [3] uses it to estimate market prices of risk after applying time series techniques to a proxy for the short rate, [10] uses it to compute parameters implied by data with different maturities.

The paper is organized as follows. In Section 2 we revise the Corzo-Schwartz convergence model of interest rates and provide the formulae for the bond prices which we will need later. Section 3 contains the algorithm for estimating the short rate in this model with a zero correlation and a sample calibration on simulated data. In Section 4 we present a simulation study which shows robustness of our algorithm; it estimates the short rate very precisely also when the data are simulated from the original correlated version of the model, as well as from its dynamic correlation modification. We apply the algorithm to real data in Section 5. Finally, we present conclusion remarks and possibilities for future research in Section 6.

\section{Corzo-Schwartz convergence model of interest rates}

In this section, we review the convergence model of interest rates [3] by Corzo and Schwarz and provide the formulae for the bond prices which we will need in our estimation procedure. Corzo and Schwartz propose the following system of stochastic differential equations for the evolution of the European interest rate $r_{e}$ and the domestic interest rate $r_{d}$ :

$$
\begin{aligned}
\mathrm{d} r_{d} & =\left(a+b\left(r_{e}-r_{d}\right)\right) \mathrm{d} t+\sigma_{d} \mathrm{~d} w_{d}, \\
\mathrm{~d} r_{e} & =c\left(d-r_{e}\right) \mathrm{d} t+\sigma_{e} \mathrm{~d} w_{e},
\end{aligned}
$$

where $w_{d}$ and $w_{e}$ are Wiener processes which can be correlated, so that

$$
\mathbb{E}\left[\mathrm{d} w_{d} \mathrm{~d} w_{e}\right]=\rho \mathrm{d} t,
$$

where $\rho$ is assumed to be constant. The European short rate is reverting to its equilibrium level $d$, the speed is given by the parameter $c>0$. Similarly, the domestic short rate is reverting to the European short rate with the speed is given by $b>0$. However, the model allows a possibility of a minor divergence 


\section{ZUZANA BUČKOVÁ-ZUZANA GIROVÁ-BEÁTA STEHLÍKOVÁ}

given by the parameter $a$. We note that this parameter has been found to be statistically insignificant when estimating it from the real data in [3], but we keep it in the formulation of the model since it does not bring any complications in the subsequent computations. Parameters $\sigma_{d}, \sigma_{e}>0$ define the variance of random fluctuations.

If we assume constant market prices of risk $\lambda_{e}$ and $\lambda_{d}$, both European and domestic bond prices can be found in a closed form. The European market is described by a classical Vasicek model [17, which has a known analytical solution for the bond price. The domestic bond prices $P=P\left(r_{d}, r_{e}, \tau\right)$ satisfy the partial differential equation which can be solved in a closed form, see [3]:

$$
\begin{aligned}
& -\frac{\partial P}{\partial \tau}+\left(a+b\left(r_{e}-r_{d}\right)-\lambda_{d} \sigma_{d}\right) \frac{\partial P}{\partial r_{d}} \\
& \quad+\left(c\left(d-r_{e}\right)-\lambda_{e} \sigma_{e}\right) \frac{\partial P}{\partial r_{e}}+\frac{\sigma_{d}^{2}}{2} \frac{\partial^{2} P}{\partial r_{d}^{2}}+\frac{\sigma_{e}^{2}}{2} \frac{\partial^{2} P}{\partial r_{e}^{2}}+\rho \sigma_{d} \sigma_{e} \frac{\partial^{2} P}{\partial r_{d} \partial r_{e}}=0
\end{aligned}
$$

for all $r_{d}, r_{e} \in \mathbb{R}$ and $\tau \in(0, T)$, where $\tau=T-t$ denotes time remaining to maturity of the bond. The initial condition is given by the payoff of the bond, i.e., $P\left(r_{d}, r_{e}, 0\right)=1$ for all $r_{d}$ and $r_{e}$. In what follows we use the reparametrization

$$
\begin{gathered}
a_{1}=a-\lambda_{d} \sigma_{d}, \quad a_{2}=-b, \quad a_{3}=b, \\
b_{1}=c d-\lambda_{e} \sigma_{e}, \quad b_{2}=c,
\end{gathered}
$$

under which the linear functions $a_{1}+a_{2} r_{d}+a_{3} r_{e}$ and $b_{1}+b_{2} r_{e}$ correspond to the coefficients standing next to the first partial derivatives in (3), as well as to the drifts of the short rate processes under the so-called risk neutral measure (see for example [9] for the risk neutral pricing and its connection to the approach using partial differential equations). Then, the closed form solution of the equation (3) has the separated form

$$
\log P\left(r_{d}, r_{e}, \tau\right)=A(\tau)-D(\tau) r_{d}-E(\tau) r_{e},
$$

where, in the generic case of $a_{2} \neq b_{2}$, the functions $A(\tau), D(\tau)$ and $E(\tau)$ are given by

$$
\begin{aligned}
D(\tau)= & \frac{-1+e^{a_{2} \tau}}{a_{2}}, \\
E(\tau)= & \frac{a_{3}}{a_{2} b_{2}} \frac{a_{2}\left(1-e^{b_{2} \tau}\right)-b_{2}\left(1-e^{a_{2} \tau}\right)}{a_{2}-b_{2}} \\
A(\tau)= & \int_{0}^{\tau}-a_{1} D(s)-b_{1} E(s)+\frac{\sigma_{d}^{2}}{2} D^{2}(s)+\frac{\sigma_{e}^{2}}{2} E^{2}(s) \\
& +\rho \sigma_{d} \sigma_{e} D(s) E(s) \mathrm{d} s .
\end{aligned}
$$

The function $A(\tau)$ can be written using only elementary functions as well, but we omit the expression for the sake of brevity. 


\section{Algorithm for estimating the short rate in a model with zero correlation}

We consider a situation in which we have market data of interest rates $R_{i j}$ with maturities $\tau_{j}$ for $j=1,2, \ldots, m$ observed at times $i=1,2, \ldots, n$. Our aim is to estimate the domestic short rate $r_{d i}$ for each observation time, together with the model parameters. We follow the approach of [13, [14] (where the following objective function was used to estimate the parameters, while the short rate was approximated by a proxy), 8, 2, (where it was used to estimate the short rate as well) and define the objective function

$$
\begin{aligned}
F & =\sum_{i=1}^{n} \sum_{j=1}^{m} w_{i j}\left(R\left(r_{d i}, r_{e i}, \tau_{j}\right)-R_{i j}\right)^{2}, \\
& =\sum_{i=1}^{n} \sum_{j=1}^{m} \frac{w_{i j}}{\tau_{j}^{2}}\left(\log P\left(r_{d i}, r_{e i}, \tau_{j}\right)+R_{i j} \tau_{j}\right)^{2},
\end{aligned}
$$

where $R$ are the interest rates computed from the bond prices implied by the model and the relation (1), and $w_{i j}>0$ are the weights. We want to minimize this objective function.

Firstly, we note that the domestic interest rate depends also on the European parameters and on the European short rate. It is reasonable to estimate them first, without taking the domestic data into account. The European part of the process may be common to various choices of the domestic interest rate and therefore, we would not want its estimate to be dependent on a particular choice of the domestic data. Estimation of the European parameters and the short rate corresponds to the estimation of the one-factor Vasicek model. This problem has been studied in 8, and the procedure from the paper yields accurate results using a simple optimization procedure - the main optimization is only one-dimensional and in order to evaluate the function at a certain point, we need to estimate one linear regression model (i.e., run a quadratic optimization problem). The first step of our algorithm is therefore an application of the algorithm from [8]. Resulting estimates of the parameters $b_{1}, b_{2}, \sigma_{e}$ and the values of the short rate $r_{e i}$ for $i=1,2, \ldots, n$ are then substituted into (77) and treated as known constants in further optimization. In this way, $F$ becomes as a function of $a_{1}, a_{2}, \sigma_{d}$ and $r_{d i}$ (since $a_{3}=-a_{2}$ in our model) for $i=1,2, \ldots, n$.

In what follows we consider the Corzo-Schwartz convergence model with $\rho=0$. In this case, the logarithm of the domestic bond price can be written in the form

$$
\begin{aligned}
\log P\left(r_{d}, r_{e}, \tau\right)=a_{1} F_{1}\left(\tau ; a_{2}\right)+\sigma_{d}^{2} F_{2}\left(\tau ; a_{2}\right)+F_{3}\left(\tau ; a_{2}\right)- \\
D\left(\tau ; a_{2}\right) r_{d}-E\left(\tau ; a_{2}\right) r_{e}
\end{aligned}
$$




\section{ZUZANA BUČKOVÁ-ZUZANA GIROVÁ-BEÁTA STEHLÍKOVÁ}

where functions $D, E$ come from the general separated form of the solution (cf. (4), (5) ) and functions $F_{1}, F_{2}$ and $F_{3}$ are given by

$$
\begin{aligned}
F_{1}\left(\tau ; a_{2}\right) & =-\int_{0}^{\tau} D\left(s ; a_{2}\right) \mathrm{d} s, \\
F_{2}\left(\tau ; a_{2}\right) & =\frac{1}{2} \int_{0}^{\tau} D^{2}(s) \mathrm{d} s, \\
F_{3}\left(\tau ; a_{2}\right) & =-b_{1} \int_{0}^{\tau} E(s) \mathrm{d} s+\frac{1}{2} \sigma_{e}^{2} \int_{0}^{\tau} E^{2}(s) \mathrm{d} s .
\end{aligned}
$$

The important property is that all these functions $D, E, F_{1}, F_{2}, F_{3}$ depend only on the parameters from the SDE governing the European short rate and the domestic parameter $a_{2}$. In our situation, when the European parameters are estimated in the first step of the calibration solely from the Euro data, then for a given value of $a_{2}$, the logarithm of the domestic bond price $\log P\left(r_{d}, r_{e}, \tau\right)$ is a linear function of parameters $a_{1}$ and $\sigma_{d}^{2}$ and the values of the domestic short rate $r_{d}$. It means that for a fixed $a_{2}$, the objective function can be minimized by estimating a (possibly weighted) linear regression. In an outer optimization problem, the optimal $a_{2}$ is found. The linear regression also gives estimates of the parameters $a_{1}, \sigma_{d}^{2}$ and the estimated evolution of the domestic short rate $r_{d}$. We remark that if using an unconstrained minimization leads to a negative value of $\sigma_{d}^{2}$, the linear regression can be replaced by a quadratic optimization with a nonnegativity constraint, which is also a computationally easy problem. However, we have not experienced this problem, neither in simulations, nor when analysing the real data.

We provide a sample calibration using parameters from [3], but replacing the value of the correlation $\rho$ by zero. The initial values of the European and domestic short rates are set to their equilibrium levels (i.e. to the values when both European and domestic drift under the real probability measures are zero) and simulate one quarter of daily data. We use Euler-Maruyama discretization to simulate the short rates, but we note that their statistical properties do not enter the objective function of the optimization process, since it is based only on the quality of fitting the yield curves. Therefore, no error is introduced by considering the short rate values simulated in this way. We simulate 12 maturities, ranging from 1 to 12 months and use them as an input for the calibration. In the objective function (77) we consider weights $w_{i j}=\tau_{j}^{2}$, following the approach used in [13], 14]. The estimation procedure given above yields very precise results, which we summarize in Tables 1 and 2, As it can be seen graphically in Figure 1, the variable of our interest, the domestic short rate, practically coincides with its estimate. 
TABLE 1. Estimates from a sample calibration: European parameters $a_{1}$, $a_{2}, \sigma_{e}^{2}$ (using algorithm from [8]) and domestic parameters $b_{1}, b_{2}, \sigma_{d}^{2}$ (algorithm proposed in this paper).

\begin{tabular}{ccc}
\hline & Parameter & Estimate \\
\hline$b_{1}$ & 0.017785 & 0.0177846 \\
$b_{2}$ & -0.208700 & -0.208703 \\
$\sigma_{e}^{2}$ & 0.000256 & 0.000256 \\
$a_{1}$ & -0.012280 & -0.012280 \\
$a_{2}$ & -3.670000 & -3.670019 \\
$\sigma_{d}^{2}$ & 0.001024 & 0.001028 \\
\hline
\end{tabular}

TABLE 2. Estimates from a sample calibration: Comparing the estimated domestic short rate $\hat{r}_{d}$ with its simulated values $r_{d}$.

\begin{tabular}{lcc}
\hline & $r_{d}-\hat{r}_{d}$ & $\left|r_{d}-\hat{r}_{d}\right|$ \\
\hline Minimum & $-4.018 \mathrm{e}-08$ & $1.647 \mathrm{e}-9$ \\
First quartile & $-9.691 \mathrm{e}-09$ & $1.243 \mathrm{e}-08$ \\
Median & $1.573 \mathrm{e}-08$ & $2.338 \mathrm{e}-08$ \\
Mean & $1.158 \mathrm{e}-08$ & $2.562 \mathrm{e}-08$ \\
Third quartile & $3.024 \mathrm{e}-08$ & $3.369 \mathrm{e}-08$ \\
Maximum & $6.893 \mathrm{e}-08$ & $6.893 \mathrm{e}-08$ \\
\hline
\end{tabular}

\section{Simulation study and the robustness of the algorithm}

We provide results from 1000 simulations for each of the following three scenarios:

(1) convergence model with zero correlation,

(2) convergence model with correlation $\rho=0.219$, as estimated by Corzo and Schwartz in 3],

(3) convergence model with dynamic correlation given by $\rho(t)=1-c_{1} e^{-c_{2} t}$ with illustrative values $c_{1}=1-0.219$ and $c_{2}=0.2$ (the value of $c_{1}$ is chosen such that at time $t=0$ the correlation coincides with that from scenario 2 , the value of $c_{2}$ is illustrative). 


\section{ZUZANA BUČKOVÁ-ZUZANA GIROVÁ-BEÁTA STEHLÍKOVÁ}

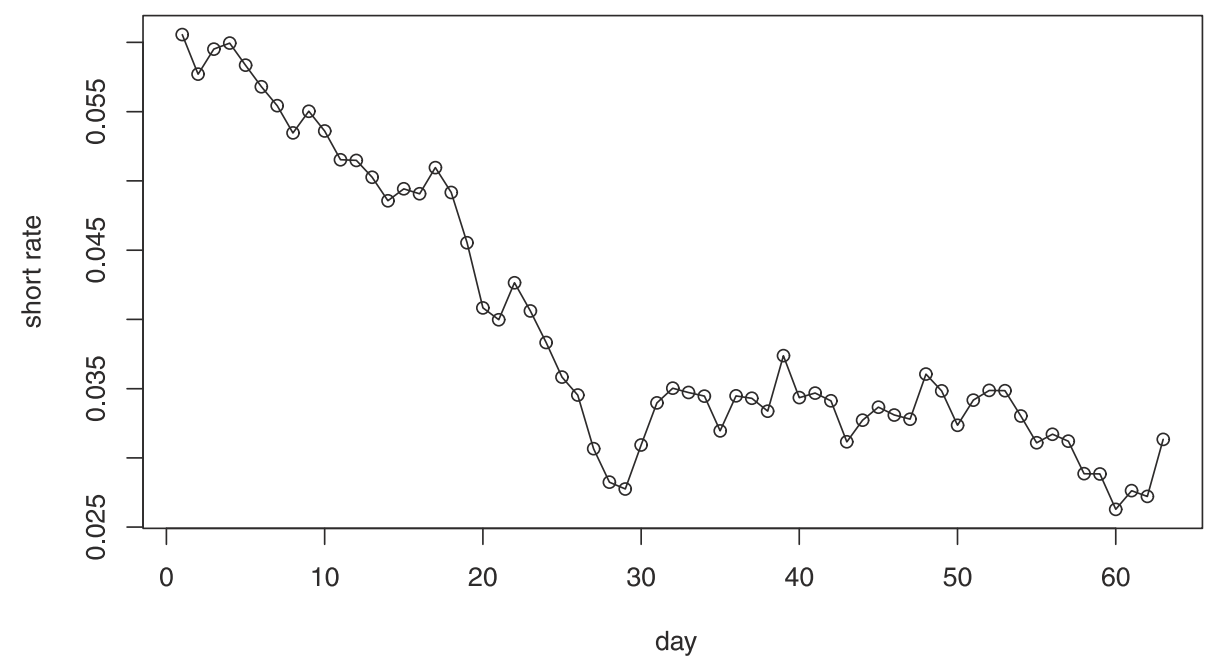

Figure 1. Estimates from a sample calibration: Comparting the estimated short rate (lines) with its simulated values (points).

In the first two scenarios we use the bond pricing using the formulae from Section 2 to compute the input data. In the first scenario, our optimization does not use an approximation of the bond prices, but there is still a small error coming from the fact that the European parameters are not exact, but estimated. In the second scenario, another error is introduced, which comes from neglecting the effect of correlation when computing the model bond prices. However, in light of the results from [7], we do not expect the error to be large, since the bond prices are not very sensitive to the value of the correlation $\rho$.

The third scenario uses a dynamic correlation. A dynamic correlation in financial markets has been studied for example in [15] (correlation between Wiener processes refers to the stochastic differential equations for a stock price and an exchange rate) and [16] (stochastic differential equations describe stock price and its volatility; they generalize the Heston model). It is meaningful also in the context of convergence models of interest rates. In the cited pioneering paper [3], the estimated correlation is higher when only more recent data were used (i.e., data closer to entering the monetary union). This, as well as a financial intuition suggests that the correlation is not constant, but it changes (in this case increases, since we model the time before joining the monetary union) in time. We denote by $\rho(t)$ the correlation at time $t$. A more detailed treatment of dynamic correlation in the context of convergence models [12] is in preparation; 
however, here we only use a simple case from it: If this dynamic correlation is introduced into the system (2) of the stochastic differential equations, the constant $\rho$ in the partial differential equation for the domestic bond price (3) is replaced by the function $\rho(t)$. It follows that the form of solution remains the same, as well as the functions $D(\tau)$ and $E(\tau)$. The only change is in the computation of the function $A(\tau)$, where the constant $\rho$ in (6) is replaced by $\rho(T-s)$ where $T$ is the maturity of the bond. In the case of the function $\rho(t)$ considered in our scenario 3 , it is possible to evaluate the function $A(\tau)$ in the closed form.

In each simulation we follow the same procedure as in the sample calibration from the previous section. Firstly, we simulate 63 observations of daily data (i.e., one quarter) for European and domestic short rates using Euler discretization. Again, we note that this approximation brings no error into the estimation of the parameters. Then, we compute the exact solution of the bond-pricing equation and we use it to obtain the term structures of interest rates for 12 maturities, ranging from 1 to 12 months. The weights $w_{i j}$ used in the estimation are given by $w_{i j}=\tau_{j}^{2}$. For each simulation we compute the absolute error of short rate estimates in each day and record its descriptive statistics: minimum, first quartile, second quartile (i.e., median), mean, third quartile and maximum.

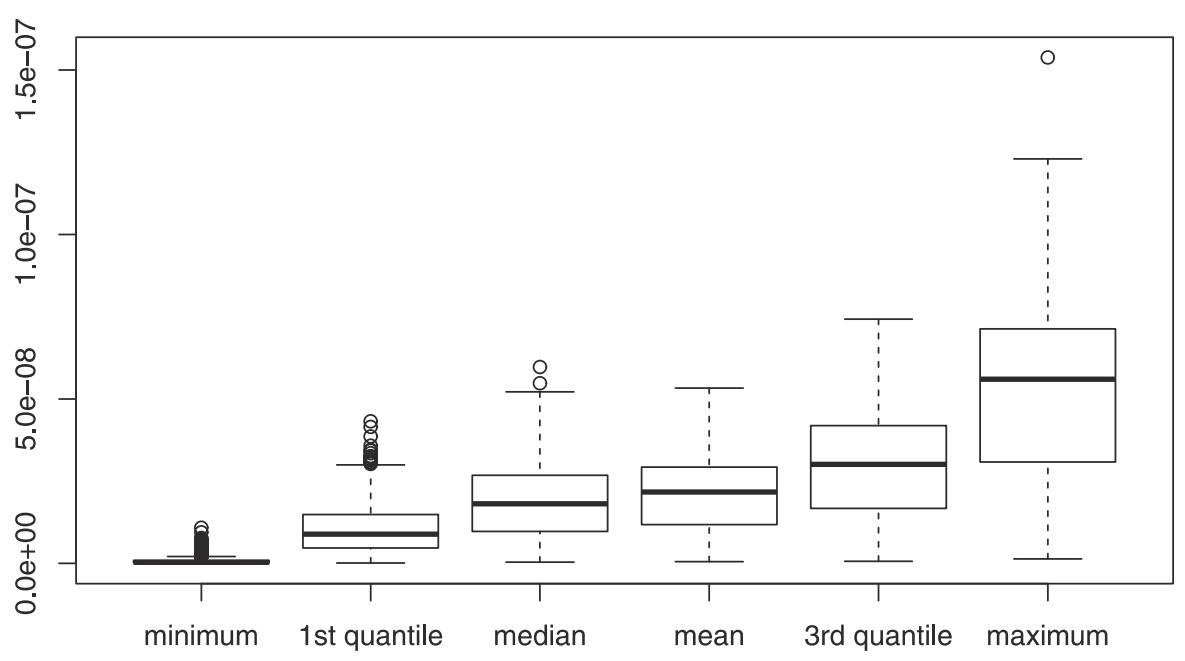

FIGURE 2. Descriptive statistics of absolute error in estimating the domestic short rates, computed for each of 1000 simulations of scenario 1 (zero correlation). 


\section{ZUZANA BUČKOVÁ-ZUZANA GIROVÁ-BEÁTA STEHLÍKOVÁ}

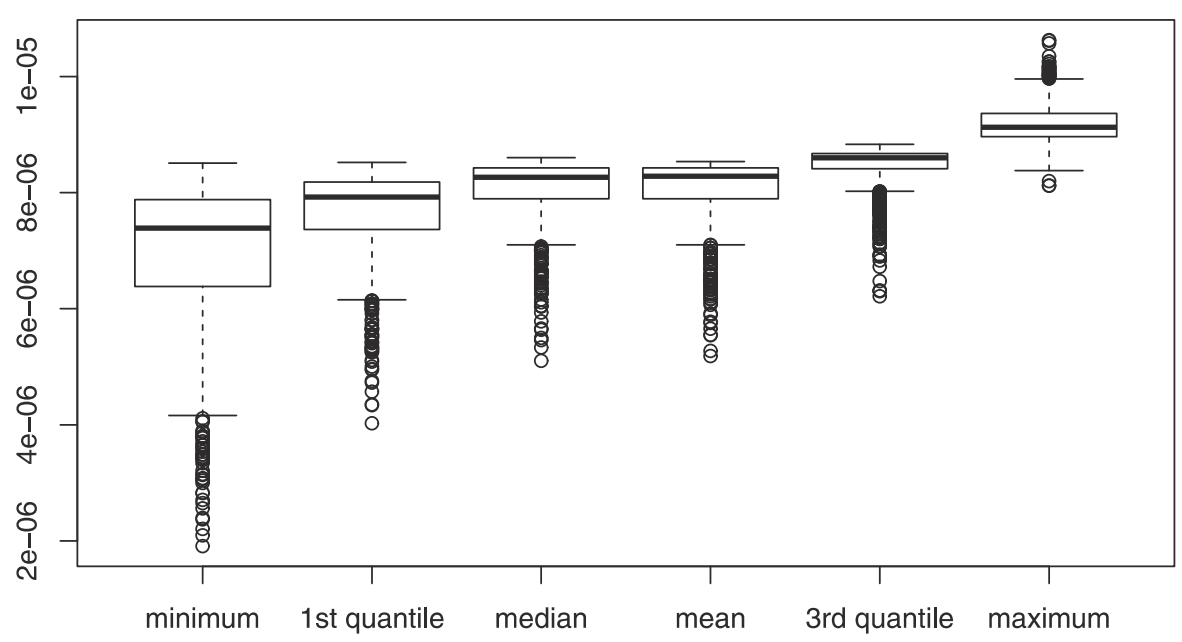

Figure 3. Descriptive statistics of absolute error in estimating the domestic short rates, computed for each of 1000 simulations of scenario 2 (constant nonzero correlation).

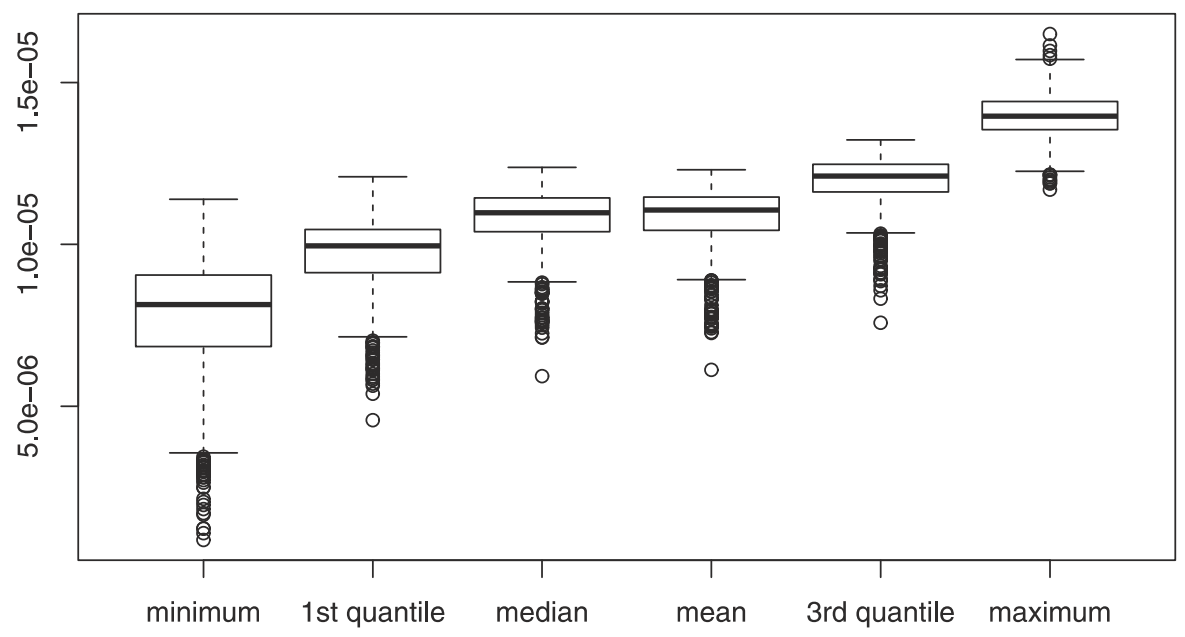

Figure 4. Descriptive statistics of absolute error in estimating the domestic short rates, computed for each of 1000 simulations of scenario 3 (dynamic correlation). 
A graphical summary of these descriptive statistics, evaluated for each of 1000 simulations, is presented by boxplots in Figures 2, 3, 4. Furthermore, we present the average values in Table 3 .

TABLE 3. Average values of descriptive statistics describing the absolute error in estimating the domestic short rate. The columns correspond to the type of correlation in the data generating processes.

\begin{tabular}{lccc}
\hline & Zero & Nonzero constant & Dynamic \\
\hline Minimum & $7.618 \mathrm{e}-10$ & $6.983 \mathrm{e}-06$ & $7.777 \mathrm{e}-06$ \\
First quartile & $1.054 \mathrm{e}-08$ & $7.490 \mathrm{e}-06$ & $9.697 \mathrm{e}-06$ \\
Median & $1.916 \mathrm{e}-08$ & $8.068 \mathrm{e}-06$ & $1.080 \mathrm{e}-05$ \\
Mean & $2.093 \mathrm{e}-08$ & $8.073 \mathrm{e}-06$ & $1.083 \mathrm{e}-05$ \\
Third quartile & $2.974 \mathrm{e}-08$ & $8.470 \mathrm{e}-06$ & $1.195 \mathrm{e}-05$ \\
Maximum & $5.183 \mathrm{e}-08$ & $9.187 \mathrm{e}-06$ & $1.397 \mathrm{e}-05$ \\
\hline
\end{tabular}

\section{Application to real data}

When the euro was first introduced in 1999 — as "book" money —, the euro area was made up of 11 of the then 15 European Union Member States. Greece joined in 2001, just one year before the cash changeover, followed by Slovenia in 2007, Cyprus and Malta in 2008, Slovakia in 2009, Estonia in 2011, Latvia in 2014 and Lithuania in 2015, see [19. In this section we study the interbank rates in the euro area and domestic countries during the last four enlargements. In each case we consider the last quarter before adopting the euro.

EURIBOR is the rate at which euro interbank term deposits are being offered within the European Union and European Free Trade Association countries by one prime bank to another at $11.00 \mathrm{a}$. m. Brussels time, see [20]. The domestic rates in Slovakia, Estonia, Latvia and Lithuania were BRIBOR, TALIBOR, RIGIBOR and VILIBOR, respectively. The data were taken from [21, [22], 23], [24], 25]. Table 4 summarizes the maturities available for every data set (the abbreviation $w$ stands for weeks and $m$ stands for months) and the number of observations. We aligned the euro and domestic interest rates and used only the dates for which both of the rates were available. We note that in October 2013, also the rates with maturities of $3 \mathrm{w}, 4 \mathrm{~m}, 5 \mathrm{~m}, 7 \mathrm{~m}, 8 \mathrm{~m}, 10 \mathrm{~m}$ and $11 \mathrm{~m}$ were available, but we used only the full time series given in the table. 


\section{ZUZANA BUČKOVÁ-ZUZANA GIROVÁ-BEÁTA STEHLÍKOVÁ}

TABLE 4. Data used in the empirical analysis.

\begin{tabular}{|c|c|c|c|c|}
\hline Year & Domestic rate & Euro maturities & Domestic maturities & Days \\
\hline 2008 & BRIBOR & $\begin{array}{l}1 \mathrm{w}, 2 \mathrm{w}, 3 \mathrm{w}, 1 \mathrm{~m}, \\
2 \mathrm{~m}, 3 \mathrm{~m}, 4 \mathrm{~m}, 5 \mathrm{~m}, \\
6 \mathrm{~m}, 7 \mathrm{~m}, 8 \mathrm{~m}, 9 \mathrm{~m}, \\
10 \mathrm{~m}, 11 \mathrm{~m}, 12 \mathrm{~m}\end{array}$ & $\begin{array}{l}1 \mathrm{w}, 2 \mathrm{w}, 1 \mathrm{~m}, 2 \mathrm{~m}, \\
3 \mathrm{~m}, 3 \mathrm{~m}, 6 \mathrm{~m}, 9 \mathrm{~m}, \\
12 \mathrm{~m}\end{array}$ & 62 \\
\hline 2010 & TALIBOR & $\begin{array}{l}1 \mathrm{w}, 2 \mathrm{w}, 3 \mathrm{w}, 1 \mathrm{~m}, \\
2 \mathrm{~m}, 3 \mathrm{~m}, 4 \mathrm{~m}, 5 \mathrm{~m}, \\
6 \mathrm{~m}, 7 \mathrm{~m}, 8 \mathrm{~m}, 9 \mathrm{~m} \\
10 \mathrm{~m}, 11 \mathrm{~m}, 12 \mathrm{~m}\end{array}$ & $1 \mathrm{~m}, 3 \mathrm{~m}, 6 \mathrm{~m}, 12 \mathrm{~m}$ & 63 \\
\hline 2013 & RIGIBOR & $\begin{array}{l}1 \mathrm{w}, 2 \mathrm{w}, 1 \mathrm{~m}, 2 \mathrm{~m}, \\
3 \mathrm{~m}, 6 \mathrm{~m}, 9 \mathrm{~m}, 12 \mathrm{~m}\end{array}$ & $\begin{array}{l}1 \mathrm{w}, 1 \mathrm{~m}, 3 \mathrm{~m}, 6 \mathrm{~m}, \\
12 \mathrm{~m}\end{array}$ & 64 \\
\hline 2014 & VILIBOR & $\begin{array}{l}1 \mathrm{w}, 2 \mathrm{w}, 1 \mathrm{~m}, 2 \mathrm{~m}, \\
3 \mathrm{~m}, 6 \mathrm{~m}, 9 \mathrm{~m}, 12 \mathrm{~m}\end{array}$ & $\begin{array}{l}1 \mathrm{w}, 2 \mathrm{w}, 1 \mathrm{~m}, 3 \mathrm{~m}, \\
6 \mathrm{~m}, 12 \mathrm{~m}\end{array}$ & 63 \\
\hline
\end{tabular}
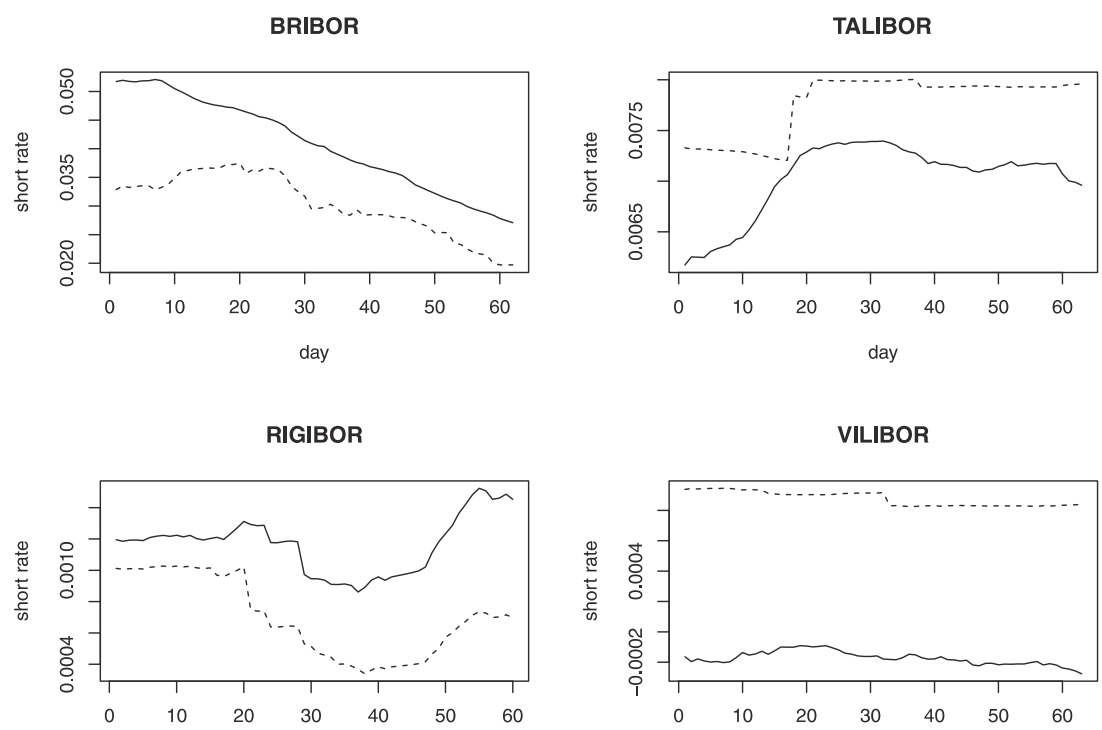

FIGURE 5. Estimates of the euro short rate (solid lines) and the domestic short rates (dashed lines). The domestic rate refers to the country which was going to adopt the euro currency - Slovakia (BRIBOR rate), Estonia (TALIBOR), Latvia (RIGIBOR) and Lithuania (VILIBOR). 
In Figure 5 we show the variables of our interest - estimated short rates in the euro area and in the domestic countries.

As a simple measure of convergence of interest rates, we compute the distance between estimated short rate in the euro area and in the domestic country. In order to take different absolute values of the rates in different years into account, we consider its ratio to the absolute value of the estimated euro short rate. These indicators are shown in Figure 6. They suggest that the convergence of the short rate was least pronounced in the case of Lithuania (these high values can be explained also by very low level of the interest rates), while the remaining three countries have our indicator of the same order. Approximately in the last two months we are able to order them by decreasing values of the indicator (i.e., increasing strength of the short rate convergence) as follows: Latvia, Slovakia, Estonia.
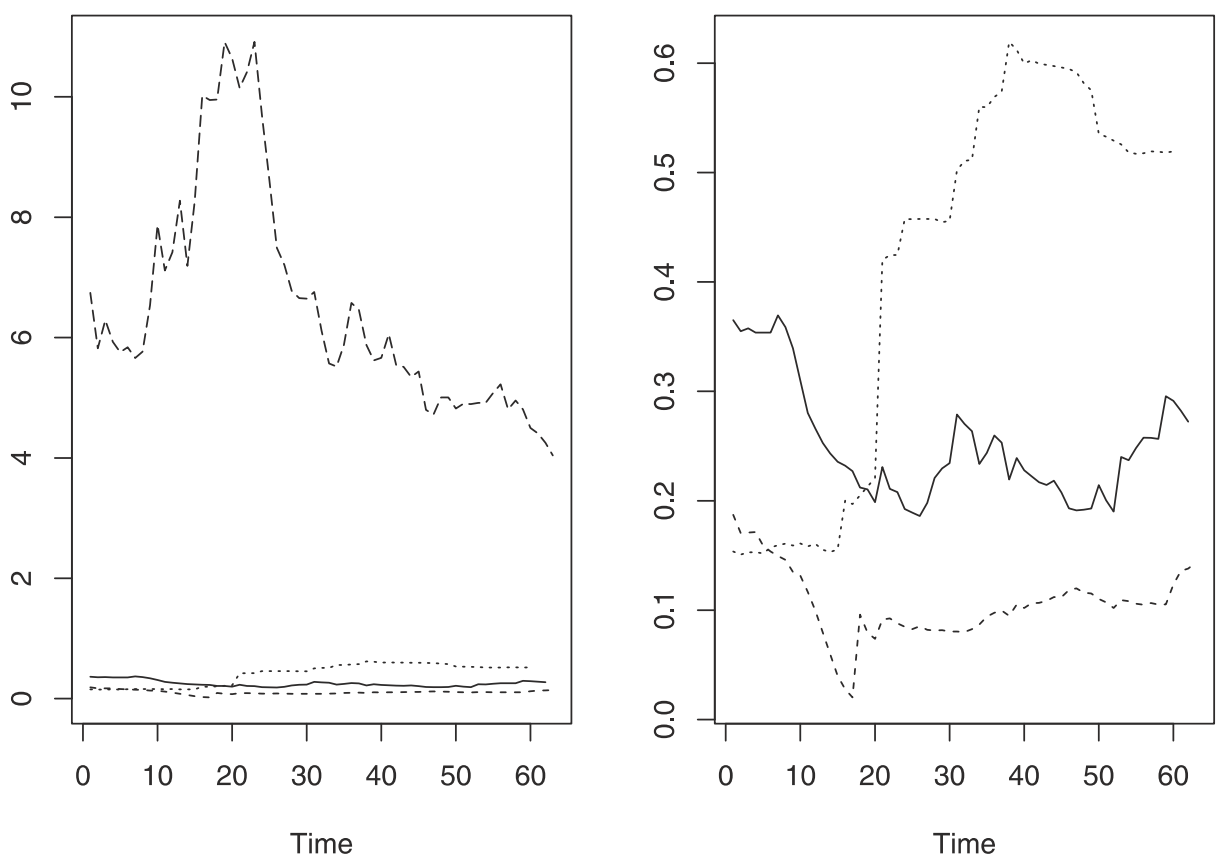

FiguRE 6. A simple indicator measuring the convergence of the short rate in the domestic country: Slovakia (solid line), Estonia (dashed line), Latvia (dotted line) and Lithuania (long-dashed line). The zoom on the right omits the long-dashed line representing Lithuania. 


\section{ZUZANA BUČKOVÁ-ZUZANA GIROVÁ-BEÁTA STEHLÍKOVÁ}

\section{Conclusions}

We proposed a method for estimating the unobservable domestic short rate from the interest rates in a convergence model with zero correlation. The least squares approach leads to a computationally easy problem: minimization of a function of one variable, while an evaluation of the function value requires running one linear regression. Simulations suggest that the algorithm is robust to the specification of correlation; it gives very precise estimates also in the case of a nonzero constant correlation as well as in the case of a dynamic correlation. Finally, we applied it to real market data and estimated the domestic short rate in the last four countries that adopted the euro currency, at the time shortly before they entered the monetary union. We suggested a simple measure of convergence of interest rates, but the question of correct and meaningful interpretation of the results obtained by our algorithm provides a lot of space for future research.

\section{REFERENCES}

[1] AIT-SAHALIA, Y.: Testing continuous-time models of the spot interest rate, Rev. Financial Stud. 9 (1996), 385-426.

[2] BUČKOVÁ, Z.-HALGAŠOVÁ, J.-STEHLÍKOVÁ, B.: Short rate as a sum of two CKLS-type processes, International Conference on Numerical Analysis and Its Applications, Springer, Cham, 2016.

[3] CORZO SANTAMARIA, T.-SCHWARTZ, E.S.: Convergence within the EU: Evidence from interest rates, Econ. Notes 29 (2000), 243-266.

[4] CORZO SANTAMARIA, T.-BISCARRI, J. G.: Nonparametric estimation of convergence of interest rates: Effects on bond pricing, Spanish Econ. Rev. 7 (2005), 167-190.

[5] COX, J. C.-INGERSOLL JR., J. E.-ROSS, S. A.: An intertemporal general equilibrium model of asset prices, Econometrica (1985), 363-384.

[6] FOUQUE, J. P.-PAPANICOLAOU, G.-SIRCAR, R.-SOLNA, K.: Multiscale stochastic volatility for equity, interest rate, and credit derivatives, Cambridge University Press, 2011.

[7] GIROVÁ, Z.-STEHLÍKOVÁ, B.: Effect of correlation on bond prices in short rate models of interest rates, Math. Morav. 22 (2018), 89-101. 
[8] HALGAŠOVÁ, J.-STEHLÍKOVÁ, B.-BUČKOVÁ, Z.: Estimating the short rate from the term structures in the Vasicek model, Tatra Mt. Math. Publ. 61 (2014), 87-103.

[9] KWOK, Y.K.: Mathematical models of financial derivatives, Springer-Verlag, Berlin, 2008.

[10] MORENO, M.-PLATANIA, F.: A cyclical square-root model for the term structure of interest rates, Eur. J. Oper. Res. 241 (2015), 109-121.

[11] STEHLÍKOVÁ, B.-BUČKOVÁ, Z.: A three-factor convergence model of interest rates, Proceedings of ALGORITMY (2012), 95-104.

[12] STEHLÍKOVÁ, B.- BUČKOVÁ, Z.: Dynamic correlation in a convergence model of interest rates, preprint.

[13] ŠEVČOVIČ, D.-URBÁNOVÁ - CSAJKOVÁ, A.: Calibration of one factor interest rate models, J. Elect. Eng. 55 (2004), 46-50.

[14] ŠEVČOVIČ, D.-URBÁNOVÁ - CSAJKOVÁ, A.: On a two-phase minmax method for parameter estimation of the Cox, Ingersoll, and Ross interest rate model, Cent. Eur. J. Oper. Res. 13 (2005), 169-188.

[15] TENG, L.-EHRHARDT, M.-GÜNTHER, M.: The pricing of Quanto options under dynamic correlation, J. Comput. Appl. Math. 275 (2015), 304-310.

[16] TENG, L.-EHRHARDT, M.-GÜNTHER, M.: On the Heston model with stochastic correlation, Int. J. Theor. Appl. Finance, 19 (2016), no. 6,

[17] VASICEK, O.: An equilibrium characterization of the term structure, J. Financ. Econom. 5 (1977), 177-188.

[18] ZÍKOVÁ, Z.-STEHLÍKOVÁ, B.: Convergence model of interest rates of CKLS type, Kybernetika 48 (2012), 567-586.

[19] What is the euro area? | European Commission, online (1. 7. 2019): https://ec.europa.eu/info/business-economy-euro/euro-area/what-euro-area_en

[20] EMMI-European Money Markets Institute | About EURIBOR, online (1. 7. 2019): https://www.emmi-benchmarks.eu/euribor-org/about-euribor.html

[21] EMMI-European Money Markets Institute | Euribor Rates, online (1. 7. 2019): https://www.emmi-benchmarks.eu/euribor-org/euribor-rates.html

[22] BRIBOR / BRIBID, online (1. 7. 2019): https://www.nbs.sk/sk/statisticke-udaje/financne-trhy/urokove-sadzby/urokove-sadzby-nbs/bribor-bribid-za-mesiac-po-dnoch

[23] TALIBOR/TALIBID, online (1. 7. 2019): http://statistika.eestipank.ee/\#/en/p/1010/r/1730

[24] Latvijas Banka RIGIBOR, online (30. 4. 2018):

https://www.bank.lv/statistika/dati-statistika/naudas-tirgus-index/ rigibid-rigibor-vesturiskie-dati 


\section{ZUZANA BUČKOVÁ-ZUZANA GIROVÁ-BEÁTA STEHLÍKOVÁ}

[25] Lietuvos Bankas, VILIBOR, online (30. 4. 2018):

http://www.lb.lt/statistics/statbrowser.aspx?group=7222\&lang=en\&orient=horz

Received August 27, 2019

Faculty of Mathematics, Physics and

Informatics

Comenius University

Mlynská dolina

SK-842-48 Bratislava

SLOVAKIA

E-mail: zuzana.zikova.buckova@gmail.com z.girova@gmail.com

stehlikova@fmph.uniba.sk 